\title{
A PESQUISA BRASILEIRA EM ANÁLISE DE NARRATIVA EM TEMPOS DE "PÓS-VERDADE"
}

\author{
The Brazilian Research in Narrative \\ Investigación brasileña en Análisis \\ Analysis in times of "Post-Truth" \\ Liana de Andrade Biar* \\ Pontifícia Universidade Católica do Rio de Janeiro (PUC-Rio), \\ Departamento de Letras, Rio de Janeiro, RJ, Brasil \\ Naomi Orton** \\ Pontifícia Universidade Católica do Rio de Janeiro (PUC-Rio), \\ Rio de Janeiro, RJ, Brasil \\ Liliana Cabral Bastos ${ }^{* * *}$ \\ Pontifícia Universidade Católica do Rio de Janeiro (PUC-Rio), \\ Departamento de Letras, Rio de Janeiro, RJ, Brasil
}

de Narrativa en tiempos de "posverdad"

\begin{abstract}
Resumo: Este artigo apresenta métodos e pressupostos teórico-epistemológicos subjacentes à pesquisa discursiva informada pela Análise de Narrativa, que combina técnicas etnográficas com diretrizes analíticas oriundas das tradições de análises discursivas e da Sociolinguística Interacional. Enfoca especialmente a relação entre o campo supramencionado e a pesquisa social transdisciplinar contemporânea, e toma como exemplos algumas das pesquisas conduzidas no âmbito do grupo de pesquisa Narrativa e Interação Social (NAVIS). Adicionalmente, busca contribuir para o debate provocado pelas crises da validade e da representação, contemplando as repercussões práticas das inovações despertadas pelo cenário da pesquisa qualitativa atual no contexto das pesquisas do grupo.
\end{abstract}

Palavras-chave: Epistemologia. Metodologia. Narrativa. Interação.

\begin{abstract}
The paper aims to examine theoretical and epistemological methods and assumptions that underpin the study of the discourse guided by the Narrative Analysis. This area of research combines ethnographic techniques with analytical directives originated from Discourse Analysis and Interactional Sociolinguistics traditions. Our focus lies particularly on the relationship between the abovementioned field of study and the contemporary transdisciplinary social research, bringing examples from some researches carried out within the research group Narrative and Social Interaction (NAVIS). Moreover, we seek to contribute to the debate ignited by representation and validity crises when contemplating the practical repercussions of innovations stirred up from the current qualitative research scenario in the context of the group's researches.
\end{abstract}

Keywords: Epistemology. Methodology. Narrative. Interaction.

\footnotetext{
* Doutora em Estudos da Linguagem. Professora Adjunta. Programa de Pós-Graduação em Estudos da Linguagem. ORCID: http://orcid.org/0000-0002-8673-8668. Email: lianabiar@gmail.com.

** Doutora em Estudos da Linguagem. Pós-Doutoranda no Programa de Pós-Graduação em Estudos da Linguagem. ORCID: http://orcid.org/0000-0001-6458-8411. Email: naomiorton@hotmail.com.

*** Doutora em Estudos da Linguagem. Professora Associada. Programa de Pós-Graduação em Estudos da Linguagem. ORCID: http://orcid.org/0000-0003-2401-3060. Email: lilianacbastos@gmail.com.
} 
Resumen: Ese artículo presenta métodos y supuestos teórico-epistemológicos subyacentes hacia la investigación discursiva informada por el Análisis de Narrativa, que combina técnicas etnográficas con directrices analíticas procedentes de las tradiciones de análisis discursivos y de la sociolingüística Interaccional. Enfoca especialmente la relación entre el campo mencionado y la investigación social transdisciplinar contemporánea, y toma como ejemplos algunas de las investigaciones conducidas en el ámbito del grupo de investigación Narrativa e Interacción Social (NAVIS). Adicionalmente, busca contribuir para el debate provocado por las crisis de la validad y de la representación, contemplando repercusiones prácticas de las innovaciones despertadas por el escenario de la investigación cualitativa actual en el contexto de las investigaciones del grupo.

Palabras clave: Epistemología. Metodología. Narrativa. Interacción.

\section{A PESQUISA NARRATIVA: BREVE APRESENTAÇÃO DO CAMPO}

A ascendência teórica do campo da Análise de Narrativa pode ser encontrada especialmente na microssociologia, nascida no contexto acadêmico americano na segunda metade do século XX (GOFFMAN, 1959, 1963; GARFINKEL, 1967; BLUMER, 1969; entre outros). Ajustando o foco e os métodos de modo a dar conta das interações cotidianas, essa abordagem realiza uma inflexão paradigmática significativa em relação aos estudos em larga escala das estruturas, sistemas e populações, uma guinada com repercussões importantes, inclusive para o campo dos Estudos da Linguagem. Uma das principais encarnações linguísticas da perspectiva "micro-escalar" foi a Sociolonguística Interacional (GUMPERZ, 1982; SCHIFFRIN, 1987; TANNEN, 1989, entre outros), que produziu um programa de investigação de orientação empírica, interessado na coconstrução de sentido em situações concretas de comunicação. A Análise de Narrativa nasce como uma ramificação dos estudos da interação: dentre outras possibilidades de delimitação de escopo, nosso "galho" abriga especificamente momentos da vida em sociedade em que cooperamos para isto que talvez seja a prática mais básica de se organizar discursivamente a experiência humana: contar histórias. Em linhas gerais, o que pesquisadores e pesquisadoras do campo da Análise de Narrativa fazem é produzir pesquisas que "dão zoom", para então tomar como objeto, os momentos em que narramos nossas vidas.

Do ponto de vista formal, um enunciado pode ser categorizado como narrativo toda vez que concatene duas ou mais orações que expressem ações em uma sequência temporal. Esta é a definição básica proposta nos estudos fundadores do campo, os de Labov e Waletsky (1968) e Labov (1972). Frequentemente, complexificamos essa estrutura produzindo prefácios, desfechos e codas. Mais tarde, na literatura, outras variações foram acrescentadas a esse esquema geral. ${ }^{1}$

Afora os critérios formais de identificação da narrativa, interessa a seus/suas analistas o que os atores sociais fazem ao narrar. Das histórias que emergem da vida cotidiana, de cenários institucionais, de entrevistas de pesquisa (também uma forma de vida social, como veremos adiante), em diferentes meios de comunicação, o que mais nos importa é sua dimensão performativa. Em suas práticas narrativas, por exemplo, as pessoas:

\footnotetext{
${ }^{1}$ Não é objetivo deste artigo apresentar pormenorizadamente o campo na Análise de Narrativa. Para uma apresentação teórica do campo, ver Bastos e Biar, 2015; Bastos, 2005 e Bastos, 2004.
} 
i. (re)criam ou sustentam, naturalizam ou desafiam crenças, valores, identidades, rótulos, categorias sociais e as expectativas a elas atreladas, ordens econômicas e políticas;

ii. organizam, conferindo sequência e coerência a suas experiências de vida;

iii. cultivam relações e negociam suas "ficções identitárias" (FABRÍCIO; BASTOS, 2009), construindo sentido sobre si mesmas;

iv. posicionam-se avaliativamente em relação a personagens, objetos, ações narradas;

v. reivindicam pertencimento e exclusão em relação a grupos sociais;

vi. condensam e tomam parte em embates discursivos.

Em resumo, narrar é uma prática discursiva constitutiva da realidade, ou, como disse Foucault, uma prática que "forma os objetos dos quais fala" (FOUCAULT, 1980, p. 49), espécie de pedra fundamental da vida social - ao menos, é nisso que apostamos de dentro desse campo. Por essa razão, a Análise de Narrativa nos convida a um exercício inevitavelmente transdisciplinar, em que desenvolvimentos oriundos de áreas diversas como sociologia, antropologia, psicologia social e estudos da linguagem se articulam em torno de questões compartilhadas.

No Brasil, a pesquisa narrativa com essa orientação tem crescido e ganhado contornos próprios, especialmente no grupo de pesquisa Narrativa e Interação Social (NAVIS) ${ }^{2}$. Gostamos de apresentar o campo como uma vertente dentre as tantas que compõem, no país, os estudos de discurso, abrigados na área de Linguística Aplicada. Neste artigo, tomaremos as pesquisas desenvolvidas no âmbito desse grupo como ilustrações para descrever o desenho metodológico, os pressupostos epistemológicos e as implicações éticas da pesquisa com que temos operado. As próximas páginas miram, então, nesta ordem: critérios de definição de temas, objetivos e perguntas de pesquisa; os procedimentos de pesquisa mais fundamentais e os modos como temos conduzido nossas análises. Em seguida, discutimos como essas escolhas se relacionam com a pesquisa social contemporânea, especialmente no que diz respeito às crises da validade e da representação.

\section{MICRO COMO PONTO DE PARTIDA DA PESQUISA NARRATIVA}

Como já foi sugerido, em Análise de Narrativa privilegiamos o "micro" como objeto de estudo. Mas por que pensamos que isso é vantajoso e o que isso significa para a prática de pesquisa? Antes de mais nada, é preciso repetir que por "micro" queremos dizer, aqui, encontros sociais. Tradicionalmente, encontros sociais são situações em que estamos face a face com um ou mais interagentes, desde aquelas mais prosaicas, como jantar, fazer compras, pegar sol, até as mais formais, como participar de uma reunião, dar aulas, rezar uma missa. Atualmente, o critério da copresença tem se afrouxado

\footnotetext{
${ }^{2} \mathrm{O}$ grupo de pesquisa Narrativa e Interação Social (CNPq) integra o PPGEL - Programa de Pós-Graduação em Estudos da Linguagem da PUC-Rio. 
significativamente de modo a contemplar ocasiões, igualmente frequentes para certos grupos, em que pessoas não necessariamente estão na companhia física uma das outras, mas ainda assim estão fazendo coisas juntas: conversando pelo whatsapp, orientando por Skype, discutindo no Facebook. Da perspectiva da Análise de Narrativa, são nesses encontros, grandes ou pequenos, todos sustentados por práticas de linguagem - sejam elas verbais ou não -, que as pessoas se engajam na (re)produção do que chamamos de vida social. Olhando para as práticas de linguagem que fundam esses encontros, podemos observar a vida social acontecendo.

Ao apostar no micro e enfatizar a agência das pessoas, não estamos em absoluto desprezando as estruturas e molduras regulatórias, ou afirmando que significados e relações sociais são produto exclusivo de interação singulares. A esse respeito, E. Goffman (1983) faz uma distinção interessante entre "ordem social" e "ordem interacional". Para o autor, a ordem interacional é uma unidade analítica substantiva por ela mesma, mas não autônoma ou anterior às estruturas analisáveis em uma ordem macrossocial. Existem diferenças estruturais (por exemplo, recursos e vantagens associados a classe, gênero e raça) que, sem dúvida, distribuem regulações e expectativas para a ordem microinteracional, mas os arranjos interacionais em que essas diferenças se manifestam podem ser diversos; não são determinações que não possam ser afrouxadas ou subvertidas no domínio do face a face. Isso quer dizer que o peso dos atributos macroestruturais pode ser definido na ordem dos encontros sociais, que por vezes consolidam, por vezes afrouxam arranjos sedimentados. Para Goffman, os contextos "micro" contêm o "macro" e vice-versa, ou, "trabalhar sobre as interações é trabalhar sobre a sociedade inteira" (GOFFMAN apud WINKIN, 1998, p. 144). A questão aqui é simplesmente explorar o que é viável à observação empírica.

A separação proposta por Goffman entre um domínio interacional e outro das estruturas sociais nos parece útil também porque, conquanto elementos como relações de poder, classe, raça e gênero informem e estejam de alguma forma pré-consolidadas no momento em que duas ou mais pessoas começam a interagir, esse encontro, quando se instancia, pode assumir contornos e processos próprios que confirmam ou afrouxam esses arranjos. Nesse sentido, a análise do micro também tem a vantagem de dar a ver a mudança social: "não apenas no nível das grandes transformações, mas como resultado acumulado e progressivo de decisões e interações cotidianas" (VELHO, 1980, p. 12).

\section{QUE ESTUDAR: TEMAS E QUESTÕES QUE NOS MOVEM}

Em qualquer área de estudo, a definição do tema de pesquisa depende fundamentalmente de curiosidades pessoais, preferências afetivas e arenas próprias de atuação. Virtualmente, qualquer grupo social ou tipo de interação pode servir de ponto de partida para se começar a planejar uma pesquisa em Análise Narrativa. Afinados com a agenda político-social da Linguística Aplicada contemporânea (MOITA LOPES, 2006), porém, temos feito esforços no sentido de privilegiar reflexões que deem visibilidade a grupos minoritários e "situações de exclusão social em diversas áreas, causadoras de sofrimento humano” (FABRÍCIO, 2006, p. 52). Demandas do cenário político atual têm nos levado frequentemente a visitar questões de gênero, raça, classe e sexualidade. Mas essa não é, naturalmente, uma lista exaustiva. 
A decisão sobre o tema vem acompanhada da delimitação de objetos discursivos específicos, a partir dos quais os temas serão explorados, e de perguntas e/ou objetivos de pesquisa - a essa altura, ainda gerais e pouco delimitados. No âmbito do grupo de pesquisa, vimos tentando adotar, como já se disse, uma perspectiva sempre transdisciplinar para pensar essas primeiras perguntas, mas essa é, obviamente, uma escolha nossa. Questões que temos sempre em mente são: como uma Análise Narrativa deste grupo ou prática social pode contribuir para a compreensão de um fenômeno social? A partir de que perguntas de pesquisa conseguimos extrapolar o próprio campo dos estudos do discurso?

O projeto atualmente conduzido por Biar (2017), por exemplo, se ocupa das narrativas de mulheres do tráfico atualmente internas do sistema penitenciário carioca. $\mathrm{O}$ objetivo da pesquisa é indagar a existência de regularidades culturalmente relevantes para o grupo, os embates discursivos sobre desvio atualizados nas narrativas e a negociação dos estigmas que envolvem a atividade criminal. Os trabalhos de Orton (2020) e Orton e Biar (2020), por sua vez, olham para as práticas narrativas que emergem em plenárias de um movimento social, com objetivo de interrogar os modos de produção política, as práticas de resistência, e a alegada horizontalidade dos movimentos sociais contemporâneos, a partir do exame das práticas narrativas. A colaboração de Bastos (MOREIRA et al., 2014) observa reuniões de trabalho de um grupo formado por profissionais de saúde, que oferece apoio a profissionais que lidam com crianças e adolescentes vítimas de violência. O objetivo da pesquisa foi observar, nas performances narrativas, embates e hierarquias que funcionavam na construção identitária do grupo em particular e na cena da saúde em geral. O importante aqui é notar que os três campos de trabalho mencionados mantêm no horizonte fenômenos que frequentam pesquisas de outras áreas (gênero e desvio; novas configurações do ativismo; relações de poder, respectivamente), com vistas a colaborar para a construção de conhecimento sobre esses assuntos a partir de uma expertise própria para lidar com dados discursivos.

Muitos outros exemplos poderiam ser acrescentados à lista. Trabalhos de outros membros e membras do NAVIS incluem narrativas de "saída do armário" (CRISTÓVÃO, 2016); narrativas sobre compulsão alimentar contadas por mulheres em conflito com o peso (SOUZA; BASTOS, 2020); testemunhos religiosos de fiéis alinhados com a Teologia da Prosperidade (FLORÊNCIO; BIAR, 2018), dentre outros contextos de pesquisa que se situam em encruzilhadas disciplinares.

\section{CAMPO, A INSPIRAÇÃO ETNOGRÁFICA E O COLAPSO DO BINÁRIO SUJEITO/OBJETO}

Se subscrevermos a ideia, brevemente explorada neste artigo, de que o mundo social só nos está disponível nas interações cotidianas e nos significados que as pessoas negociam nessas interações, então a Análise de Narrativa está inescapavelmente destinada a observar esses atores em ação. De fato, e na esteira de outros estudos de falaem-interação, nossos procedimentos de pesquisa frequentemente incluem algum tipo de trabalho de campo ou reflexão etnográfica para auxiliar a interpretação dos dados discursivos. Essa dimensão etnográfica pode, no entanto, tomar muitas formas. 
Em nosso grupo de pesquisa observamos, por exemplo, nos trabalhos de Biar (2012) e Cruz e Bastos (2015), um formato de incursão de campo mais próximo de uma etnografia clássica, que inclui observação participante densa e continuada de comunidades com limites bem circunscritos. Nos dois casos, respectivamente, a observação da rotina de uma instituição prisional e de uma ONG de atendimento a obesos mórbidos informou ativamente as análises de narrativas de seus membros(as).

Diferentemente, Teixeira e Biar (2019), após encontrarem algumas barreiras para realizar observação participante de em uma comunidade caiçara no interior do Rio de Janeiro, optaram por descrever microecologicamente um evento de letramento proposto por uma das autoras, que, além de pesquisadora, tem formação pedagógica. A pesquisa seguiu então escrutinando as ações situadas que constituíram o evento - dentre elas várias práticas narrativas - aproximando-se da prática da Etnografia da Comunicação (ERICKSON, 1992).

Já o trabalho de Lewis (2016), pode ser caracterizado como um trabalho que se beneficiou do que hoje tem sido chamado de etnografia virtual, digital ou netnografia (cf. HINE, 2015). A autora focaliza um grupo de discussão online formado por simpatizantes da prática sexual do pegging. Além de se debruçar sobre as narrativas dos usuários, com vistas a construir entendimento sobre noções de gênero e sexualidade que circulam nessa comunidade, Lewis se integra ao grupo como observadora-participante e apresenta uma descrição minuciosa de suas práticas naquele ambiente virtual.

Há ainda os estudos que flertam com a etnografia de si ou a autoetnografia ${ }^{3}$. Em geral, isso acontece quando a participação do(a) pesquisador(a) no contexto investigado se inicia antes e independentemente do estudo em si. As pesquisas de Orton (2020) e Araújo (2015) exploram narrativas e práticas discursivas de movimentos sociais das quais as duas eram membras ativas desde antes da investigação se iniciar, e o trabalho envolve, como não poderia deixar de ser, reflexões importantes acerca desse duplo estatuto de participante e pesquisadora.

Seja qual for o formato da reflexão etnográfica levada a cabo por seus pesquisadores e pesquisadoras, uma tônica do grupo tem sido a tentativa de dar mais ênfase à forma como se interage com a comunidade investigada, a partir do entendimento de que ele/ela é parte das ações conjuntas praticadas pelo grupo.

Essa perspectiva nos parece também uma maneira legítima de se lidar com o famoso "paradoxo do observador", formulado pelo sociolinguista W. Labov (1972, p. 29). O paradoxo pode ser enunciado da seguinte maneira: a pesquisa linguística deve observar como as pessoas falam quando não estão sendo sistematicamente observadas; no entanto, só podemos obter esses dados por observação sistemática. Do ponto de vista do NAVIS, esse paradoxo não é um problema a ser superado, desde que a presença (corpórea ou digital) do(a) pesquisador(a) em campo se converta em dado analisável. Aceitando-se como participante pleno do campo, o(a) pesquisador(a) pode aprofundar sua compreensão dessa condição, sem tentar minimizar sua "intromissão" no contexto da pesquisa. Com isso, colapsa o binário sujeito/objeto, isto é, a separação presumida entre o(a)

\footnotetext{
3 A respeito dos variados usos de uma reflexão (auto)etnográfica nos estudos do discurso, ver: http://www.ufjf.br/revistaveredas/files/2018/08/Apresenta\%C3\%A7\%C3\%A3o_Veredas_2018_1.pdf 
pesquisador(a) e o objeto de estudo. Adicionalmente, essa perspectiva confere a vantagem de ajudar a desestabilizar as relações de poder pesquisador(a)/pesquisado(a), enraizadas nas etnografias clássicas sobre culturas distantes.

A observação de si-em-atividade-de-pesquisa também oferece a possibilidade para nós, bem-vinda - de se discutir com honestidade em que medida as "histórias pessoais [dos(as) pesquisadores(as)] saturam a investigação etnográfica" (GERGEN; GERGEN, 2006, p. 369). Em nossas pesquisas, assumimos que os dados serão sempre filtrados pela mirada do(a) pesquisador(a), e as interpretações guiadas pelas lentes ideológicas de seu contexto sociocultural e histórico. Ou seja, o processo de conhecimento da vida social implica, necessariamente, um grau de subjetividade, o qual não é mais visto como indesejável, já que integra o próprio projeto de conhecimento da alteridade (COELHO, 2016, p. 10) ${ }^{4}$.

\section{GERAÇÃO DE DADOS NARRATIVOS E A ENTREVISTA COMO CENA SOCIOLÓGICA}

Apesar do flerte com a reflexão etnográfica, o cerne de nosso trabalho investigativo está na geração e gravação (ou captura, nos casos de interações escritas em ambientes digitais) de dados linguístico-discursivos, que posteriormente serão tratados e analisados a partir de técnicas próprias do campo dos estudos do discurso e da fala-em-interação.

Embora, ao longo da existência do grupo de pesquisa, nos tenhamos dedicado a gerar narrativas em eventos interacionais diversos, tais como atividades pedagógicas, grupos de discussão online, programas de televisão, reuniões institucionais, plenárias e manifestações de rua, para este artigo, por razões de espaço, focalizamos mais detidamente nosso método de geração de dados mais frequente: a entrevista qualitativa de pesquisa.

Em lugar de serem tomadas como mero procedimento metodológico para se obter informações de um entrevistado transmissor de um self integrado (GUBRIUM; HOLSTEIN, 2003), as entrevistas qualitativas são aqui analisadas como qualquer outro contato interacional ${ }^{5}$ (MISHLER, 1986), um encontro social entre pesquisador(a) e demais participantes da pesquisa, com sequências a serem descritas e analisadas como tais. Em poucas palavras: as entrevistas nos interessam porque põem atores sociais pesquisadores(as) e demais participantes - em relação, fazendo emergir narrativas também orientadas para essa relação. Como acontecimentos localizados, as narrativas respondem a propósitos focais de performance interacional (BAUMAN, 1986), tendo em vista este outro, presentificado, que é o entrevistador.

\footnotetext{
${ }^{4}$ A reflexão apurada sobre os modos como o(a) pesquisador(a) altera, ou instaura, o (um novo) campo explica por que razão a seção 5 deste artigo prefere "geração" a "coleta" de dados.

${ }^{5}$ Há, na literatura dos estudos da fala-em-interação, uma discussão importante sobre a necessidade de se operar com dados naturalísticos, isto é, aqueles que existiriam independentemente da interferência do(a) pesquisador(a). A esse respeito, conferir Garcez (2008).
} 
Tais interações podem ser simétricas, descontraídas, mas também tensas, angustiadas, cheias de tato, em que um mal-estar precisa ser enfrentado a partir do manejo de impressões (GOFFMAN, 1959). Levar o já citado paradoxo do observador às últimas consequências significa pensar a entrevista de pesquisa como uma cena sociológica que merece análise per se. Um bom exemplo disso é o trabalho de Albuquerque (2017), que, depois de observar e entrevistar mulheres na fila de visitação de um presídio masculino, analisa em detalhes as interdições, hesitações e mitigações que compuseram a negociação do estigma de ser mãe ou companheira de sujeitos encarcerados.

Após a gravação das entrevistas, outros processos precisam ser observados com cuidado, como a transcrição do que foi gravado. Transcrições ortográficas são, certamente, formas imperfeitas de se representar as interações orais, e, para reduzir a discrepância entre os dados gravados e sua imitação gráfica, procuramos incluir detalhes suficientes para a identificação dos chamados aspectos suprassegmentais e paralinguísticos (prosódia, entonações, ritmo, silêncios etc.). As convenções simbólicas para realizar essas marcações podem variar significativamente em função das características que cada trabalho precisa apresentar. De qualquer forma, mesmo acrescentando essas marcas, a transcrição continua sendo apenas uma aproximação da oralidade. Isso porque o processo de transcrição acaba sempre guiado pelos sentidos dos transcritores - que, mesmo quando máquinas, apresentam capacidades variadas de perceber as características físicas do que se ouve. Por essa razão, todo processo de transcrição é compreendido como uma etapa já interpretativa (MISHLER, 1986; RIESSMAN, 1992; GARCEZ, 2002), guiada pelos olhos, e pelo ouvido, do(a) pesquisador(a).

A transcrição nos faz também lidar com o grande inconveniente de tornar, por vezes, os dados ininteligíveis para eventuais leitores de demais disciplinas, ou para um público externo aos círculos acadêmicos. Esse é um efeito indesejável, que precisamos enfrentar. No NAVIS, temos tentado achar um meio-termo entre a necessidade de incrementar a qualidade da transcrição e a legibilidade do texto para interlocutores gerais.

Por vezes, o processo de tornar os dados possíveis para o público-alvo pode envolver outras escolhas de representação, que vão além do uso de convenções de transcrição. No já mencionado estudo etnográfico voltado para uma comunidade online, em que as interações se desenvolviam na língua inglesa, Lewis (2016) precisou levar em consideração mais uma camada interpretativa: a tradução dos dados para a língua portuguesa. Por compreender esse processo como ideológico, transformador e performativo, a autora explicita as escolhas envolvidas. Segundo ela, o discurso do contexto investigado apresentou diversos desafios para o processo de tradução, pois comumente apresentava gírias e jogos de palavras que só faziam sentido em língua inglesa. Diante desse impasse, Lewis optou por criar novas expressões que, em português, comunicariam a multiplicidade de significados presente no texto fonte. Além disso, notas foram incluídas a fim de ampliar a visibilidade da atividade tradutória e das escolhas envolvidas nesse processo. 
O objetivo desta seção é apontar um caminho para o tipo de análise qualitativa e interpretativista que orienta a produção do NAVIS. Para tornar esses apontamentos mais concretos, apresentamos uma narrativa ainda inédita, gerada como parte do já mencionado projeto coordenado por Biar (2017). Resumidamente, nessa proposta de pesquisa, interessa (i) compreender a partir de que repertórios simbólicos mulheres presas por tráfico de drogas compreendem a experiência desviante e (ii) problematizar essa compreensão no contexto de embates discursivos de que elas fazem parte.

Os dados gerados até agora formam um corpus de 17 entrevistas. Esse número pode causar certo estranhamento para quem vem de outras áreas de pesquisa. Que tipo de generalização é possível a partir de 17 entrevistas? Quem tem alguma experiência com análise qualitativa de dados de fala, no entanto, sabe que 17 entrevistas podem constituir um corpus gigantesco. No campo da Análise de Narrativa, operamos com cautela com noções como as de "amostragem" e "saturação". O número de entrevistas a ser realizado dependerá sempre de muitos fatores, mas principalmente do tipo de pergunta que se faz aos dados. Em se tratando de orientações analíticas qualitativas, como é nosso caso, estamos mais interessadas nas "intensidades" (MINAYO, 2017) dos fenômenos, do que na busca de generalizações ou relações de causa e efeito. Por vezes, uma só entrevista pode gerar insights sobre a sociedade interessantíssimos, se considerarmos, como Gadamer (2008 apud MINAYO, 2017), que toda individualidade é manifestação do viver total, embora não seja a totalidade do viver. Dito de outra maneira: um único enunciado, uma única narrativa, necessariamente encapsula uma multidão de outros, com os quais se relaciona. Desde que sua relação metonímica com a história e a sociedade esteja justificada, o empreendimento de pesquisa pode consistir em puxar cada um desses componentes, mostrando, simultaneamente, suas relações entre si, suas relações com o contexto imediato em que foi produzido, e com as condições políticas, econômicas e institucionais que propiciam seu acontecimento.

Quando foi entrevistada, Jô era uma jovem interna do sistema penitenciário fluminense, cumprindo pena por tráfico, tendo recentemente progredido para regime semiaberto. O encontro com ela se deu fora da cadeia, no turno da tarde, período do dia em que ela podia se ausentar da instituição penal desde que com propósito de trabalhar ou estudar. Nesse encontro, gravado em um telefone celular, Jô pôde narrar momentos de sua história de vida que na teoria narrativa costumamos chamar de eventos com reportabilidade estendida (LINDE, 1993), isto é, eventos sustentados culturalmente - e por isso sentidos individualmente pelas pessoas - como os mais relevantes de sua biografia, a ponto de serem muitas vezes contados e recontados em diferentes situações sociais. Dentre esses eventos, destacam-se episódios em que a mãe e o irmão de Jô foram presos, sua própria incursão no tráfico de drogas e, finalmente, sua prisão. 
Apresentamos a seguir um pequeno trecho dessa entrevista, representada graficamente seguindo a ortografia padrão, acrescida propositalmente de poucas convenções de transcrição: ${ }^{6}$

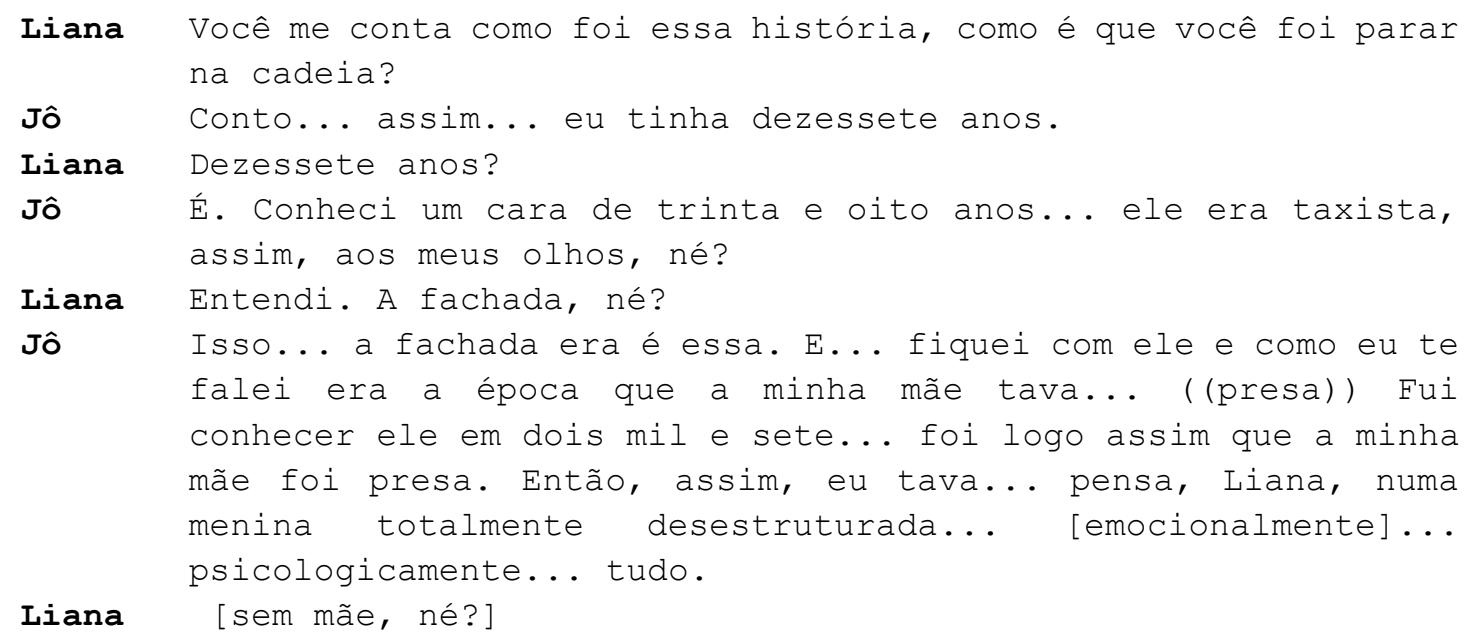

Na tentativa de organizar o trabalho analítico, subdividimos o exame desse pequeno dado em três diferentes lâminas de observação. A depender da complexidade da pesquisa proposta, o(a) analista pode concentrar seus esforços em uma, duas ou todas elas. Nessas laminações, operamos a partir da materialidade linguística e interacional dos dados, que entendemos serem índices que apontam para o contexto sociocultural mais amplo ${ }^{7}$, espécie de nexo entre as dimensões micro e macro. Realizar essa ligação é o cerne do trabalho interpretativo em análises discursivas ${ }^{8}$.

Chamamos de "categorias de análise" (ou "pistas indexicais") os tipos de índices potencialmente analisáveis nos dados. Por exemplo, se estamos vasculhando as operações sintáticas que ordenam as ações narrativas, dizemos que nossa categoria é a "sequencialidade", se estamos analisando o modo como outras vozes e enunciados são convocados em uma narrativa, nossa categoria é a "intertextualidade"; se estamos analisando as palavras escolhidas, nossa categoria é a "seleção lexical", e assim por diante. Essas categorias podem vir de diferentes tradições discursivas, as possibilidades são muitas, e por vezes, a mesma categoria receberá nomes diferentes nas várias vertentes de análise de discurso. Aqui optamos por, sempre que possível, usar um vocabulário mais acessível para não nos estendermos em definições que desviariam o foco do que é o objetivo deste artigo: sensibilizar o leitor para o espírito da Análise Narrativa, sem distrações teóricas por ora desnecessárias. De qualquer forma, vale lembrar que esse é um momento em que frequentemente nos hibridizamos a outras tradições de análise, tomando emprestadas, por vezes, categorias já bem estabelecidas em áreas vizinhas.

\footnotetext{
${ }^{6}$ Legenda: (?): entonação ascendente; (.): entonação descendente; (...): pequena pausa; ([ ]): momento de sobreposição de falas.

${ }^{7}$ Para o conceito de indexicalidade, ver especialmente Silverstein (1976).

${ }^{8}$ Por sugestão de parecerista deste artigo, explicitamos que, em nosso trabalho, compreendemos discurso como ação sobre o mundo, e a análise discursiva, conforme sugerido pelos programas de inspiração foucaultiana, como análise das práticas (regulares, coletivas, históricas, contextualizadas) que não descrevem, mas produzem de forma sistemática os objetos dos quais falam (FOUCAULT, 1969).
} 


\subsection{PRIMEIRA LÂMINA: ANÁLISE DA ESTRUTURA NARRATIVA}

No âmbito do NAVIS, recomendamos que a primeira etapa analítica consista em identificar e descrever a estrutura das narrativas, seus principais movimentos retóricos, as relações de sequencialidade, causalidade e coerência (LINDE, 1993). De onde essa história começa? Até onde ela vai? O que constitui seu prefácio, sua ação complicadora, resolução e coda? Que avaliações são feitas durante a história e o que tudo isso indexa em relação ao modo como Jô se posiciona em relação aos personagens e ações narradas $?^{9}$ Essas são perguntas de pesquisa bem delimitadas que uma análise dos dados deve ser capaz de responder diretamente. Estaremos preocupados, neste momento, em como Jô e sua interlocutora organizam formalmente a sua entrada para o crime.

No pequeno excerto apresentado, nota-se, por exemplo, que Jô localiza o início de seu envolvimento com o tráfico em uma certa faixa etária (muito jovem) e equaciona esse evento ao casamento com um "cara" (infere-se, um traficante). Nessa ocasião, apaixonada e fragilizada, especialmente pela prisão da mãe (causa), Jô teria sido acometida por alguma coisa que ela descreve como uma espécie de cegueira (efeito), que a leva (agência reduzida) ao que foi omitido neste excerto: a entrada para o tráfico.

Ainda que não tenhamos usado uma metalinguagem técnica, nota-se que essa primeira lâmina usa categorias relacionadas à estrutura narrativa (vindas, por exemplo de trabalhos como o de LABOV, 1972; LINDE, 1993) para dar conta do evento narrado isto é, a história em si. Ao esmiuçar a construção da história, começamos a produzir interpretações sobre as próximas lâminas, mais centradas na dimensão performativa do discurso.

\subsection{SEGUNDA LÂMINA: ANÁLISE DA INTERAÇÃO}

De natureza pragmático-interacional, essa lâmina lança luz sobre a ordem interacional, ou seja, a dimensão situada em que as narrativas foram coproduzidas pelos(as) participantes. Trata-se, portanto, do exame do evento narrativo - o momento em que se narra. Categorias analíticas oriundas da Sociolinguística Interacional e da Análise da Conversa podem ser úteis para responder perguntas tais como: quais são as demandas expressivas do encontro? Como as narrativas e a construção de si do narrador podem estar respondendo a essas demandas? Em meio a que sequência de ações interacionais a narrativa emergiu? Que ação ela mesma parece performar essa sequência? Como os(as) participantes cooperam na construção da história? Como eventuais desconfortos e constrangimentos interacionas são negociados?

De volta a nosso exemplo, não podemos deixar de discutir as implicações acerca de a fala de Jô ser dirigida a uma pesquisadora, e não, por exemplo, à mãe dela. Também não podemos ignorar que essa pesquisadora apresenta todas as características normativas (branca, de classe média, professora universitária), que contrastam com a posição estigmatizada da entrevistada na situação. $\mathrm{O}$ encontro pode ser enquadrado como aquilo

\footnotetext{
${ }^{9}$ As perguntas propostas aqui não são exaustivas.
} 
que Goffman (1988) denomina "encontro misto", um tipo de encontro que põe em relação norma e desvio, e cria uma série de demandas de sustentação de imagem projetada. A esse respeito, é digno de nota o "Pensa, Liana, uma menina totalmente desestabilizada”, uma marca formal do evento narrativo, em que Jô retorna ao aquie-agora da interação, alinhando-se à entrevistadora e a crenças que circulam no senso comum sobre feminilidade.

As respostas da entrevistadora e a última linha de Jô realizam um trabalho micropolítico importante nesse sentido, de cancelamento do estigma e calibragem das posições entre as duas: a entrevistadora "passa recibo" da "absolvição" moral de Jô, ao concordar com ela. Esse tipo de marca desmonta, no plano da interação, as tensões do encontro misto, suas assimetrias, numa espécie de mitigação das marcas estigmatizantes.

\subsection{TERCEIRA LÂMINA: OS EMBATES DISCURSIVOS}

Esta é a lâmina que, finalmente, busca mapear os discursos emergentes na cadeia de enunciados (BAKHTIN, 1979) da qual a(s) narrativa(s) sob escrutínio participa(m). Estamos aqui em um nível mais "macro" de interpretação discursiva, olhando para vozes e visões de mundo que extrapolam o local específico de enunciação e o sujeito que as enuncia, e que habitam o contexto da pesquisa. Nos perguntamos, aqui: quais são os discursos que participam dos embates para legitimar sentido (MOITA LOPES, 2001) concernentes ao nosso contexto de pesquisa? Em que condições e conjunturas sóciohistóricas eles foram/são produzidos? Que índices apontam para esses discursos? Como os(as) participantes parecem estar se posicionando em relação a esses discursos (Aderindo? Naturalizando? Contestando?).

O que estamos chamando aqui simplesmente de "discurso" recebeu diversos nomes nas muitas tradições de análise discursiva que povoam o cenário acadêmico atual: sistemas de coerência (LINDE, 1990), grandes narrativas (SHOSHANA, 2013), Discurso - com "D" maiúsculo (GEE, 1999), entre outros. O nome, aqui - e as vertentes teóricas que ele instaura -, importa menos que a noção de existência de uma crença/compreensão/ideia que, de tão frequente, repetida e legitimada por instituições, resiste (mas por vezes é desafiada) em falas/textos particulares, concretos.

$\mathrm{Na}$ análise sequencial da narrativa de Jô, é digno de nota que, após ser perguntada sobre a idade com que foi presa, ela responde: "dezessete anos". Depois de um pedido de confirmação, esclarece que dezessete anos não foi a idade com que ela foi presa, mas a idade em que ela conheceu o marido traficante. Nota-se aí, como já dito, o envolvimento amoroso sendo indiretamente apontado como causa da prisão, uma responsabilização indireta do marido por seu desvio. Outras causas que decorrem dessa associação entre a relação amorosa e a entrada para o crime é a juventude da narradora, a irracionalidade e desestruturação consequente da prisão da mãe. Jô parece estar produzindo aqui uma justificativa para sua entrada para o tráfico, de modo a conformá-la ou ressignificá-la com base em discursos altamente infecciosos (BRIGGS, 2007): o da feminilidade "emotiva", do amor romântico que cega e emburrece. A partir daí, podemos começar a pensar em quais são os discursos que, ainda que não indexados diretamente por Jô, frequentam as explicações para a adesão criminal, especialmente no caso de mulheres. Além de, claro, que conjunturas históricas e culturais favorecem a adesão ou a reação a tais discursos. 
Propusemos aqui três lâminas analíticas, mas elas não necessariamente precisam ser entendidas como etapas diferentes da análise. Na verdade, essas três lâminas frequentemente se sobrepõem - os mesmos excertos realizam ações em três níveis. Como exemplo, podemos pensar em como a adesão ao discurso da feminilidade hegemônica, apontado aqui como examinável pela terceira lâmina, faz também um trabalho interacional - portanto segunda lâmina - de mitigação do estigma, dirimindo assimetrias morais entre as interlocutoras. Embora esse tipo de sobreposição esteja sempre presente em nossas pesquisas, temos insistido nas laminações como forma de organizar o trabalho analítico tentando não perder de vista que uma boa análise precisa dar conta tanto da ordem social quanto da ordem interacional.

\section{PERSPECTIVA (ONTO)EPISTEMOLÓGICA E CRISE DA VALIDADE}

Até aqui, estivemos desenvolvendo o desenho metodológico típico dos trabalhos que produzimos. A partir agora, e pelas próximas duas seções, refletimos um pouco mais detidamente sobre as bases (onto)epistemológicas de nossas opções metodológicas. Começamos por sublinhar três pressupostos que atravessaram boa parte do que foi dito aqui; nossas apostas em relação a como concebemos a realidade social e a construção de conhecimento sobre ela:

(i) Entendemos a realidade social como um efeito de práticas discursivas, isto é, saldo das práticas de linguagem de atores sociais agindo em conjunto, negociando e pondo em circulação sentidos e valores para pessoas, ações e objetos. Também entendemos que essas práticas, embora agentivas, são constrangidas dentro de molduras socioculturais estabilizadas, isto é, rígidas, mas passíveis de transformação graças à relação dialética que mantêm com as práticas discursivas.

(ii) Concebemos também a atividade de pesquisa como uma dessas práticas interpretativas contextualmente situadas (DENZIN; LINCOLN, 2006), e descartamos a possibilidade de se chegar a um "gabarito", ou interpretação definitiva, para as práticas investigadas. Ao contrário, toda a atividade de pesquisa compõe um terreno fértil, no qual convivem múltiplas interpretações possíveis - todas filtradas pela lente subjetiva do(a) pesquisador(a) e pelo caminho teórico-epistemológico trilhado (DENZIN; LINCOLN, 2006; GERGEN; GERGEN, 2006; SCHWANDT, 2006). Nessa direção, entendemos que prática de pesquisa gera sempre "verdades parciais" porque "a ciência está nos processos históricos e linguísticos e não acima deles" (CLIFFORD, 2016, p. 32);

(iii) Entendemos que tanto a construção social da realidade quanto a interpretação desta por parte dos(as) pesquisadores(as) se dão, inevitavelmente, a partir de posições ocupadas por esses agentes em um mundo também criado na e pela linguagem. Decorre daí que toda prática de linguagem - inclusive a prática de pesquisa - toma "partido", ou seja, está imbricada a interesses políticos, ideológicos e relações de poder; assume um 
"lado" em uma disputa sobre o sentido. Cabe ainda dizer, a esse respeito, que assumir a natureza posicionada do conhecimento, para usar uma expressão infelizmente frequente em nossos dias, não é o mesmo que doutrinar. Isso porque, tal como toda prática de linguagem, fazer pesquisa é uma atividade dialógica (BAKHTIN, 1992), que responde, antecipa ou polemiza com outras práticas interpretativas, anteriores e posteriores, igualmente informadas histórica e ideologicamente. Uma prática doutrinária seria justamente aquela que evita o embate, que concebe a interpretação como limite da realidade.

Estudar a sociedade a partir dessas bases - antiessencialistas e não-objetivistas nos convoca a confrontar vozes divergentes, para que a autoridade tradicional do(a) pesquisador(a) possa concorrer com outros pontos de vista, e uma visão mais ampla do fenômeno possa ser alcançada. De certa maneira, essa confluência de vozes advém da multiplicidade de valores concorrentes e, muitas vezes, contraditórios, tanto daqueles que acompanham nossas pesquisas como participantes, quanto de nós mesmos(as). Adota-se aqui a perspectiva de uma "subjetividade nômade" (BRAIDOTTI, 1995, p. 84, apud GERGEN; GERGEN, 2006, p. 379), que rompe com a concepção de uma identidade autêntica ou estável e assume que o campo da pesquisa pode conter heterogeneidades. Cabe, portanto, ao pesquisador(a) permitir que os(as) participantes deem expressão a toda esta complexidade e variedade de contradições (GERGEN; GERGEN, 2006, p. 379-380).

A fim de contemplar outras versões daquilo que estudamos, bem como enfrentar perspectivas eventualmente divergentes, pode-se buscar diálogo dentro da comunidade acadêmica ou com participantes do contexto da pesquisa, entre outras possibilidades. No intuito de compreender como os(as) participantes entendem suas próprias ações, as transcrições e as análises dos dados gravados podem ser compartilhados, convidando-os a opinar (SCHWANDT, 2006). A exemplo disso, Orton (2020), em seu estudo sobre a construção discursiva da horizontalidade nos movimentos sociais contemporâneos, tem buscado compartilhar suas transcrições com pesquisadores(as) para além do grupo de pesquisa. Isto permite o confronto com vozes divergentes, possibilitando a reflexão sobre pensamentos por vezes enraizados em tradições distintas. Além disso, a pesquisadora tem procurado o compartilhamento dos dados com as próprias participantes da pesquisa, o que contribui para o processo de transcrição, viabilizando novas interpretações e uma "representação distribuída" (GERGEN; GERGEN, 2006, p. 377) dos dados. Apesar dos esforços para retornar os dados aos(às) participantes da pesquisa, estes não devem ser vistos como juízes das interpretações; no máximo fornecerão relatos, também posicionados e contingentes de suas ações ou intenções.

Gergen e Gergen (2006, p. 373-374), consideram que isso, a chamada "crise da validade" nas ciências humanas e sociais, nos oferece uma oportunidade para reconceituar a própria noção de validade: se, como e toda disputa de sentido, a validade é conquistada, mantida e subvertida, importa então, aos(às) pesquisadores(as), debruçar-se sobre como esses processos se dão, ou seja, indagar a partir de que meios diferentes pesquisadores(as) chegam a diferentes noções de validade e diferentes representações de determinados fenômenos. 


\section{VERDADES EFÊMERAS EM TEMPOS DE "PÓS-VERDADE"}

A desconfiança sobre a validade na pesquisa científica muitas vezes nos vulnerabiliza a críticas segundo as quais pesquisas norteadas por uma perspectiva nãoobjetivista podem servir aos interesses da chamada "pós-verdade" (ANGERMULLER, 2018 , p. 2), ou seja, o espraiamento escalar de "verdades alternativas" que parecem popularizar a máxima nietzschiana segundo a qual "não há fatos, apenas interpretações". Consideramos, nesta seção, duas questões importantes para o debate.

Primeiramente, como diferenciar um projeto epistemológico que desconfia de e relativiza os modos de produção de conhecimento de empreitadas anticientificistas como o terraplanismo, o movimento antivacina, etc, se viemos defendendo até aqui que descobertas da ciência certamente não são fixas e estáveis e que, frequentemente, o conhecimento científico é marcado por rupturas paradigmáticas radicais que deslocam nossas certezas sobre as coisas do mundo?

Sem dúvida, teorias são criadas dentro de sistemas de produção, circulação e legitimação de conhecimento atravessados por contingências histórico-culturais, materiais e relações de poder. A substituição da explicação da gravidade de Newton pela de Einstein é um bom exemplo de que, mesmo nas ciências "duras", o conhecimento sobre a natureza do mundo segue em construção. Mas o problema dos adeptos da pósverdade - e tomemos aqui por um instante o caso específico dos terraplanistas - não parece ser a ousadia de disputar uma verdade sobre a Terra bem sedimentada e legitimada pelas instâncias de poder. A questão, nos parece, é que, em benefício de uma "opinião" baseada em suas próprias percepções sobre o mundo, algumas empreitadas desse tipo ignoram monológica e arrogantemente elementos que são parte importante do debate científico em torno de seu tema de pesquisa (métodos, teorias, evidências, etc). Em outras palavras: no lugar de termos uma disputa baseada em diálogo plural, com exame e debate de um repertório amplo de vozes e experiências concorrentes, o que temos é a criação de um sistema alternativo de interação bem mais limitado, alimentado exclusivamente por adeptos das mesmas ideias.

Além disso, quando defendemos a centralidade das práticas discursivas na construção da realidade, estamos nos referindo a realidades sociais ou impressões de realidade provocadas por significados atribuídos às coisas do mundo. Não podemos negar a realidade "material" de, por exemplo, nossos órgãos sexuais ou de nossas funções reprodutivas, mas podemos dizer que os significados que atribuímos a essas coisas, na vida social, moldam o que conhecemos sobre elas. Podemos, por exemplo, tomá-los como indicadores de gênero masculino ou feminino, ou questionar essa associação binária (BUTLER, 1990); podemos compreendê-los como fonte de prazer ou pecado; podemos tomar a reprodução como compulsória e definidora de nossas identidades ou não. Embora os órgãos sexuais, em si, não sejam de natureza discursiva, como dizem Cameron e Kulick (2003, p. 19), é "a linguagem [que] produz as categorias pelas quais organizamos nossos desejos, identidades e práticas sexuais". Acreditamos que a indagação constante, informada, cuidadosa e de mão dupla sobre os limites entre o natural e o construído socioculturalmente, embora difícil, seja fundamental para não cairmos em um anticientificismo vazio. 
Uma segunda questão com que temos de lidar quando subscrevemos a ideia de que todos são capazes de produzir versões ou teorias para os fenômenos que interpretam é que, embora essas produções não sejam em si mesmas ranqueáveis ou definitivas, algumas delas são mais ratificadas e valorizadas por razões institucionais, políticas e históricas. A respeito disso, o NAVIS tem tentado se engajar em práticas contrahegemônicas de construção de conhecimento, que se definem pelo compromisso político e ético com a transformação social, ou, mais especificamente, com a desnaturalização de "situações de exclusão social em diversas áreas, causadoras de sofrimento humano" (FABRÍCIO, 2006, p. 52). Nesse sentido, fazemos escolhas metodológicas no intuito de privilegiar vozes tradicionalmente silenciadas. Embora, como já dissemos, a narrativa produzida pelo(a) pesquisador(a) possa buscar a inclusão de múltiplas perspectivas a fim de melhor compreender seu objeto, nunca conseguirá contemplar todas ou atingir o status de uma versão definitiva. Sendo assim, a pesquisa preocupada com a justiça social prioriza as interpretações tradicionalmente ignoradas, buscando romper com "sentidos históricos viciados", além de:

\footnotetext{
movimentar o ângulo de observação do centro (isto é, dos países desenvolvidos e dos discursos e epistemes ocidentalistas neles produzidos) para as franjas do sistema globalizado, para as organizações invisíveis, para as periferias, para as formas de ser consideradas subalternas ou inferiores. (FABRÍCIO, 2006, p. 51).
}

$\mathrm{O}$ enfoque conferido às opiniões e às experiências de grupos sociais menos privilegiados objetiva distribuir "capital simbólico" (BOURDIEU, 1998), por entender que algumas versões da "verdade" já têm circulação ampla, enquanto outras precisam ser urgentemente ouvidas e reconhecidas (SOUZA SANTOS, 2007). A esse respeito, em nosso grupo de pesquisa, buscamos evitar aquilo que Souza Santos (2007, entre outros) tem chamado de "epistemicídio", isto é, a citação de algumas poucas pessoas - em geral homens brancos, oriundos de instituições reconhecidas no norte global - em detrimento das chamadas "vozes do sul". Este fenômeno, também concebido como "a lógica da celebridade do campo acadêmico" (ANGERMULLER; HAMANN, 2019), desestimula o debate público plural tão relevante para uma compreensão ampliada da vida social e para a análise das diferentes interpretações em relação às "suas implicações, motivações e resultados para o mundo social" (FABRÍCIO, 2006, p. 62). Dessa forma, "podemos orientar nossas ações por valores e juízos éticos, tendo em vista não valores universais, mas sim valores democraticamente definidos na esfera pública e no diálogo aberto" (FABRÍCIO, 2006, p. 62).

\section{POLÍTICAS DE REPRESENTAÇÃO NA CONSTRUÇÃO DO TEXTO DE PESQUISA}

Esta última seção trata dos modos como lidamos com um desdobramento da crise da validade, a chamada "crise da representação"; isto é, a suspeição sobre o texto de pesquisa social apontar de modo transparente para o fenômeno investigado. Sem exaurir a questão, discutimos a seguir algumas opções que fazemos ao entextualizar nossas pesquisas em relatórios, artigos, teses e dissertações. 
A produção do texto de pesquisa em nossa área envolve um processo narrativo duplo. Operamos a partir de dados narrativos, coproduzidos pelos(as) participantes, e interpretamos esses dados dando forma a outro texto narrativo: o texto de pesquisa. Nessa empreitada, procuramos prestar atenção nos modos como descrevemos o outro, num esforço em direção ao que Coelho (2016, p. 10) chamou de: "política das representações". Como nos alertam Bauman e Briggs (2006, p. 211), o processo de descontextualização e recontextualização na elaboração da pesquisa produz repercussões éticas $\mathrm{e}$ epistemológicas. O que pode parecer simples decisões redacionais são importantes para manter nossos posicionamentos consistentes.

Em primeiro lugar, o investimento político do(a) pesquisador(a) não deve ser ocultado em um registro ostensivamente objetivo. Se defendemos até aqui ser necessário explicitar o processo da construção da pesquisa, explorando o papel da biografia do(a) pesquisador(a) que atua nele (SCHWANDT, 2006), uma escrita mais pessoal é mais que uma opção estilística, mas uma prerrogativa dessa visão de ciência. Não queremos dizer com isso que o texto necessariamente tenha de estar em primeira pessoa: cada pesquisador(a) obviamente deve tomar as suas próprias decisões de escrita. A orientação que tem guiado o NAVIS é: não trate como discurso, como construção, apenas o que vem do outro. Frequentemente, e por vezes sem nos dar conta, nossas opiniões e interpretações aparecem travestidas de fatos e certezas, excluindo explicações alternativas por meio de soluções retóricas que silenciam o dissenso. É nesse sentido que, conforme há muito discutido na antropologia contemporânea sobre a compreensão do texto etnográfico como um gênero literário (CLIFFORD; MARCUS, 1986), reforçamos a ideia de que aquilo que o texto "conta" não é a versão única daquilo que se estuda.

A concepção do texto elaborado pelo(a) pesquisador(a) como uma "ficção", entretanto, não precisa ser vista, necessariamente, como um "ataque à razão" (DENZIN; LINCOLN, 2006, p. 22). Preferimos pensar que este seja um ponto de partida para a reflexão sobre o processo de construção de conhecimento, a fim de democratizá-lo. Para Gergen e Gergen (2006, p. 380-384), o ato de escrever convida o público a uma determinada forma de relação, sendo necessário examinar que tipo de relação é construída. Os textos tradicionais tendem a sustentar estruturas de privilégios, uma vez que o(a) pesquisador(a) escreve a partir de uma posição de "detentor de conhecimento" para um público que "não detém" tal conhecimento. O gênero acadêmico tende a fazer com que o texto fique isolado do exame de um público mais amplo, muitas vezes apresentando características monológicas, como já dissemos, que restringem as possibilidades de interação com vozes diversas. Nesse sentido, a reimaginação do processo de redação encontra-se inseparável do debate sobre o fomento de práticas democráticas. Com isso em mente, e inspirados na fala de Michelle Fine (1998), Gergen e Gergen indagam:

\footnotetext{
(Q)ue elementos da pesquisa qualitativa são atraentes, em termos produtivos, em relação às práticas democráticas/revolucionárias; em relação à organização da comunidade; às políticas sociais progressistas; a um envolvimento público democratizante com a crítica social? (2006, p. 384)
} 
Se, como já propusemos, consideramos a visibilidade ampliada das pautas de grupos marginalizados um dos objetivos da pesquisa social, a urgência em focalizar as vozes advindas desses grupos, envolvendo-as mais ativamente na construção da pesquisa, torna-se fundamental para provocar uma reflexão conjunta a partir da (re)interpretação de suas experiências. A inclusão de tal processo na escrita do trabalho permite a conscientização do leitor, bem como a construção de solidariedade, ao mesmo tempo que produz inteligibilidade sobre o fenômeno (FRASER, 1999; MENDEZ, 2013). Os(as) participantes também podem ser envolvidos na redação do texto, estimulando a justaposição das posições do(a) pesquisador(a) com as dos(as) participantes. A inclusão dessas vozes que clamam por expressão, tradicionalmente restringidas e orquestradas pela voz autoral do(a) pesquisador(a), potencializa a produção de um texto polivocal, no sentido bakhtiniano. A elaboração de um texto em que, nas palavras de Coelho (2016, p. 9), "a voz do informante somente se faria presente de forma mediada e editada pelo etnógrafo", constitui apenas mais um modo de reivindicar uma "autoridade etnográfica", em vez de favorecer a criação de um texto dialógico e polifônico.

Em relação a este aspecto ainda há um grande caminho a percorrer. Sem dúvida que, no NAVIS, apostamos na possibilidade de as pessoas e grupos sociais atuarem como agentes das explicações sobre si e os fenômenos que protagonizam - por isso analisamos suas narrativas. Acreditamos que este seja um passo para se colocar à prova, como diz Becker (2007), o privilégio dos cientistas sobre as representações sociais. Por outro lado, nossas escritas ainda estão longe de concretizar em todos os aspectos a democratização e "imundização" (BORBA; LOPES, 2018) do texto acadêmico. Este é apenas o pontapé inicial da discussão.

\section{REFERÊNCIAS}

ALBUQUERQUE, N.C. Mulheres na fila de visitação: a construção discursiva da inocência de parentes presos em narrativas vicárias. 2017. 165 f. Dissertação (Mestrado em Estudos da Linguagem) - Faculdade de Letras, Pontifícia Universidade Católica do Rio de Janeiro, Rio de Janeiro, 2017.

ANGERMULLER, J. Truth after post-truth: for a Strong Programme in Discourse Studies. Palgrave Communications, v. 30, n. 4, s.p., 2018.

ANGERMULLER, J.; HAMANN, J. The celebrity logics of the academic field: the unequal distribution of citation visibility of Applied Linguistics professors in Germany, France and the United Kingdom. Journal for Discourse Studies, v.1, n.1 p. 77-93, 2019.

ARAÚJO, E. P. "Não tá acontecendo nada e eles passam pra tocar um terror": repressão policial e construções identitárias em narrativas de manifestantes de junho de 2013. 2015. 134 f. Dissertação (Mestrado em Estudos da Linguagem) - Faculdade de Letras, Pontifícia Universidade Católica do Rio de Janeiro, Rio de Janeiro, 2015.

ARAUJO, E. P.; BIAR, L. A.; BASTOS, L. C. Engagement in social movements and the fight for justice: a study on the narratives of black mothers. Trabalhos em Linguística Aplicada, Campinas, v. 59, p. 16881709, 2020.

BAKHTIN, M. Estética da criação verbal. Tradução a partir do francês por Maria Ermantina Galvão Gomes Pereira. Revisão da tradução Marina Appenzeller. São Paulo: Martins Fontes, 1992.

BASTOS, L. C. Narrativa e vida cotidiana. Scripta, v. 7, n. 14, p. 118-127, 2004.

BASTOS, L. C. Contando estórias em contextos espontâneos e institucionais - uma introdução ao estudo da narrativa. Calidoscópio, São Leopoldo, v. 3, n. 2, p. 74-87, 2005. 
BASTOS, L. C.; BIAR, L. A. Análise de narrativa e práticas de entendimento da vida social. DELTA: Documentação de Estudos em Linguística Teórica e Aplicada, São Paulo, v. 31, n. especial, p. 97-126, 2015.

BAUMAN, R.; BRIGGS, C. Poética e performance como perspectiva crítica sobre a linguagem e a vida social. Revista de Antropologia, v. 8, n. 1, p. 185-229, 2006.

BAUMAN, R. Story, performance and event: contextual studies of oral narrative. Cambridge: Cambridge University Press, 1986.

BECKER, H. S. Segredos e truques da pesquisa. Rio de Janeiro: Jorge Zahar, 2007.

BIAR, L. A. Realmente as autoridades veio a me transformar nisso: narrativas de adesão ao tráfico e a construção discursiva do desvio. 2012. 246 f. Tese (Doutorado em Estudos da Linguagem) - Faculdade de Letras, Pontifícia Universidade Católica do Rio de Janeiro. Rio de Janeiro, 2012.

BIAR, L. A. Ação, estigma e resistência: estudo discursivo das feminilidades periféricas no Brasil. Projeto de Pesquisa (Edital Universal/CNPq) - Faculdade de Letras, Pontifícia Universidade Católica do Rio de Janeiro. Rio de Janeiro, 2017.

BLUMER, Herbert. Simbolic Interactionism. New Jersey: Ed. Prentice-Hall, 1969.

BOURDIEU, P. Escritos de educação. Petrópolis: Vozes, 1998.

BORBA, R.; LOPES, A. Escrituras de gênero e políticas de différance: imundície verbal e letramentos de intervenção no cotidiano escolar. Linguagem \& Ensino, Pelotas, v.21, n. esp., p. 241-285, 2018.

BRIGGS, C. Anthropology, Interviewing, and Communicability in Contemporary Society. Current Anthropology, v. 48, n. 4, p. 551-581, 2007.

BUTLER, J. Problemas de gênero: feminismo e subversão da identidade. Rio de Janeiro: Civilização Brasileira, 1990 [2017].

CAMERON, D; KULICK, D. Talking sex and thinking sex: the linguistic and discursive construction of sexuality. In: CAMERON, D.; KULICK, D. Language and Sexuality. Cambridge: CUP, 2003. p. 15-43.

CLIFFORD, J. Verdades parciais. In: CLIFFORD, J.; MARCUS, G. (Org.). A escrita da cultura: poética e política da etnografia. Rio de Janeiro: EDUERJ, 2016 [1986]. p. 31-61.

COELHO, M, C. Sobre tropas e cornetas: apresentações à edição brasileira de writing culture. In: CLIFFORD, J.; MARCUS, G (Org.). A escrita da cultura: poética e política da etnografia. Rio de Janeiro: EDUERJ, 2016. p. 7-26.

CRISTÓVÃO, L. S. Negociações com o armário: homossexualidades e estigma em narrativas de história de vida. 2016. 256 f. Tese (Doutorado em Estudos da Linguagem) - Faculdade de Letras, Pontifícia Universidade Católica do Rio de Janeiro, Rio de Janeiro, 2016.

CRUZ, C. A. G.; BASTOS, L. C. . HIstórias de uma obesa: a teoria dos posicionamentos e a (re)construção discursiva das identidades. Linguagem em (Dis)curso, Tubarão, v. 15, n. 3, p. 367-384, set./dez. 2015.

DENZIN, N. K.; LINCOLN, Y. S. A disciplina e a prática da pesquisa qualitativa. In: DENZIN, N. K. e LINCOLN, Y. S. (Org.). O planejamento da pesquisa qualitativa: Teorias e abordagens. Porto Alegre: Artmed, 2006. p. 15-41.

ERICKSON, F. Ethnographic microanalysis of interaction. In: LeCOMPTE, M. D.; MILLROY, W. L.; PREISSLE, J. (Org.). The handbook of qualitative research in education. New York: Academic Press, 1992. p. 201-225.

FABRÍCIO, B. F. Linguística Aplicada como espaço de desaprendizagem: redescrições em curso. In: MOIRA LOPES, L. P. (Org.). Por uma linguística aplicada indisciplinar. São Paulo: Parábola, 2006. p. 45-65.

FABRICIO, B. F.; BASTOS, L. C. Identidade de grupo: a memória como garantia do "nós face ao 'outro"”. In: PEREIRA, M. G. D.; BASTOS, C. R. P.; PEREIRA, T. C. (Org.). Discursos sócio-culturais em interação: Interfaces entre a narrativa, a conversação e a argumentação: navegando nos contextos da escola, saúde, empresa, mídia, política, gênero e migração. Rio de Janeiro: Garamond, 2009. p. 39-66.

FAIRCLOUGH, N. Discourse and social change. Cambridge: Polity Press, 1992.

FAIRCLOUGH, N. Analysing Discourse: Textual Analysis for Social Research. London: Routledge, 2003.

BIAR, Liana de Andrade; ORTON, Naomi; BASTOS, Liliana Cabral. A pesquisa brasileira em análise de narrativa em tempos de "pós-verdade". Linguagem em (Dis)curso - LemD, Tubarão, SC, v. 21, n. 2, p. 231-251, maio/ago. 2021. 
FLORENCIO, A.; BIAR, L. A. Do capitalismo produtivo ao capitalismo financeiro: construção da coerência em testemunhos neopentecostais de prosperidade. Domínios de Lingu@gem, v. 12, p. 92-120, 2018.

FOUCAULT, M. A arqueologia do saber. Tradução de L. F. B. Neves. Rio de Janeiro: Forense Universitária, 1997 [1969].

FOUCAULT, M. Power/knowledge. Selected interviews and other writings. New York: Pantheon, 1980.

FRASER, N. Redistribuição ou reconhecimento? Classe e status na sociedade contemporânea. In: Interseções, v. 4, n. 1, p. 7-32, 2002.

GARCEZ, P. Transcrição como teoria: a identificação dos falantes como atividade analítica plena. In: MOITA LOPES, L. P.; BASTOS, L. C. (Org.). Identidades: recortes inter- e multidisciplinares. Campinas, SP: Mercado de Letras, 2002. p. 83-96.

GARCEZ, P. M. A perspectiva da Análise da Conversa Etnometodológica sobre o uso da linguagem em interação social. In: LORDER, L. L.; JUNG, N. M. (Org.). Fala-em-interação social: uma introdução à Análise da Conversa Etnometodológica. Campinas, SP: Mercado de Letras, 2008. p. 17-38.

GARFINKEL, H. Studies in Ethnomethodology. New Jersey: Prentice Hall, 1967.

GEE, J. P. An introduction to discourse analysis: Theory and method. London: Routledge, 1999.

GERGEN, M.M.; GERGEN, K. J. Investigação qualitativa: tensões e transformações. In: DENZIN, N. K., LINCOLN, Y. S. (Org.). O planejamento da pesquisa qualitativa: teorias e abordagens. Porto Alegre, Artmed, 2006. p. 367-388.

GOFFMAN, E. A representação do Eu na vida cotidiana. Petrópolis: Vozes, 1989[1959].

GOFFMAN, E. Estigma: notas sobre a manipulação da identidade deteriorada. Rio de Janeiro: Guanabara, 1988.

GOFFMAN, E. The Interaction Order: American Sociological Association, 1982 Presidential Address. American Sociological Review, v. 48, n. 1, p. 1-17, 1983.

GUBRIUM, J.; HOLSTEIN, A. From the individual interview to the interview Society. In: GUBRIUM, J.; HOLSTEIN, A. (Org.). Handbook of interview research: context and method. London: Sage, 2003. p. 3-32.

GUMPERZ, J. Discourse Strategies. Cambridge: Cambridge University Press, 1982.

HINE, C. Ethnography for the internet: embedded, embodied and everyday. London: Bloomsbury Academic, 2015.

LABOV, W. The transformation of experience in narrative syntax. In: LABOV, W. Language in the inner city. Philadelphia: University of Philadelphia Press, 1972. p. 354-397.

LABOV, W.; WALETZKY, J. Narrative Analysis. In: HELM, J. (Org.). Essays on the verbal and visual arts. Seattle: U. of Washington Press, 1967. p. 12-44.

LEWIS, E. Acho que isso foi bastante macho pra ela: Reforço e subversão de ideologias heteronormativas em performances narrativas digitais de praticantes de 'pegging'. 2016. $333 \mathrm{f}$. Tese (Doutorado em Estudos da Linguagem) - Faculdade de Letras, Pontifícia Universidade Católica do Rio de Janeiro, Rio de Janeiro, 2016.

LINDE, C. Life stories: the creation of coherence. Oxford: OUP, 1993.

MENDEZ, M. Autoethnography as a research method: Advantages, limitations and criticisms. Colombian Applied Linguistics Journal, v.15, n. 2, p. 279-287, 2013.

MINAYO, M. C. Amostragem e saturação em pesquisa qualitativa: consensos e controvérsias. Revista Pesquisa Qualitativa, v. 5, n. 7, p. 1-12, 2017.

MISHLER, E. Research interviewing: context and narrative, Cambridge: Harvard University Press, 1986.

MOITA LOPES, L. P. Práticas narrativas como espaço de construção das identidades sociais: uma abordagem socioconstrucionista. In: RIBEIRO, B. T. et al. (Org.) Narrativa, identidade e clínica. Rio de Janeiro: Ipub, 2001. p. 55-72.

MOREIRA, M.; BASTOS, O. M.; BASTOS, L. C.; SANCHEZ, R. N. Violência contra crianças e adolescentes com deficiência: narrativas com conselheiros tutelares. Ciência e Saúde Coletiva, v. 19, p. 3871-3877, 2014.

ORTON, N.; BIAR, L. A. Horizontality and gender in contemporary social movements. Narrative Inquiry, v. 30, p. 236-270, 2020.

BIAR, Liana de Andrade; ORTON, Naomi; BASTOS, Liliana Cabral. A pesquisa brasileira em análise de narrativa em tempos de "pós-verdade". Linguagem em (Dis)curso - LemD, Tubarão, SC, v. 21, n. 2, p. 231-251, maio/ago. 2021. 
ORTON, N. Práticas de atropelamento, práticas de resistência: dinâmicas de gênero e a construção discursiva da horizontalidade nos movimentos sociais contemporâneos. 2020. 205 f. Tese (Doutorado em Estudos da Linguagem) - Faculdade de Letras, Pontifícia Universidade Católica do Rio de Janeiro. Rio de Janeiro, 2020.

RIESSMAN, C.K. Narrative Methods for the Human Sciences. Los Angeles: Sage, 2008.

SCHIFFRIN, D. Discourse markers. Cambridge: Cambridge University Press, 1987.

SCHWANDT, T. Três posturas epistemológicas para a investigação qualitativa: interpretativismo, hermenêutica e construcionismo social. In: DENZIN, N. K.; LINCOLN, Y. S. (Org.). O planejamento da pesquisa qualitativa: Teorias e abordagens. Porto Alegre: Artmed, 2006. p. 192-217.

SHOSHANA, A. Translating a national grand narrative into a personal biographies: Alternative biographies among siblings in everyday life. Narrative Inquiry, v. 23, n. 1, p. 171-191, 2013.

SILVERMAN, D. (Ed.) Qualitative research: theory, methods and practice. London: Sage, 1997.

SILVERSTEIN, M. Shifters, linguistic categories, and cultural description. In: BASSO, K. H.; SELBY, H. A. Meaning in Anthropology. Albuquerque: University of New Mexico Press, 1976. p. 11-55.

SOUZA, R. F.; BASTOS, L. C. A construção do sofrimento em narrativas cíclicas sobre dieta. In: BARCELOS; AMARO; PRADO (Org.). Consumos alimentares em cenários urbanos: múltiplos olhares. Rio de Janeiro: Gramma; EdUERJ, 2020. p. 419-447.

TANNEN, D. Talking Voices: repetition, dialogue, and imagery in conversational discourse. Cambridge England; New York: Cambridge University Press, 1989.

TEIXEIRA, J.; BIAR, L. A. Desalinhos caiçaras: identidades tradicionais em xeque na (tentativa de) construção de um projeto de educação diferenciada. Pensares em Revista, v. 14, p. 28-51, 2019.

VELHO, G. Observando o familiar. In: VELHO, G. (Org.) Individualismo e cultura: notas para uma antropologia da sociedade contemporânea. Rio de Janeiro: Jorge Zahar, 1980. p.123-132.

WINKIN, Y. Descer ao campo. In: WINKIN, Y. A Nova Comunicação: da teoria ao trabalho de campo. Campinas: Papirus, 1998. p. 129-146.

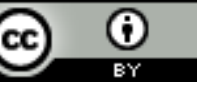

Este texto está licenciado com uma Licença Creative Commons Atribuição 4.0 Internacional

BIAR, Liana de Andrade; ORTON, Naomi; BASTOS, Liliana Cabral. A pesquisa brasileira em análise de narrativa em tempos de "pós-verdade". Linguagem em (Dis)curso - LemD, Tubarão, SC, v. 21, n. 2, p. 231-251, maio/ago. 2021. 